\title{
Assessment of Gap Junction Protein Beta-2 rs3751385 Gene Polymorphism in Psoriasis Vulgaris
}

\author{
Elli-Anna Stylianaki ${ }^{a}$, Anthony Karpouzis ${ }^{b}$, Gregory Tripsianis ${ }^{\mathrm{c}}$, \\ Stavroula Veletza ${ }^{a, d}$
}

\begin{abstract}
Background: Gap junction protein beta 2 (GJB2) upregulation in psoriasis transcriptome analysis as well as connexin 26 (Cx26, encoded by GJB2) expression upregulation in psoriatic plaques has already been substantiated. GJB2 rs72474224 and rs3751385 have been correlated with psoriasis vulgaris incidence in Chinese populations. Here we study the effect of rs3751385 in patients suffering from psoriasis vulgaris in a Caucasian Greek population at the prefecture of Thrace in Northern Greece.
\end{abstract}

Methods: One hundred and seventy-three (111 males and 62 females) psoriatic patients (108 were of early-onset psoriasis) and 171 matched controls were included in the study. Genomic DNA was extracted from peripheral blood leukocytes and genotyping was carried out by polymerase chain reaction-restriction-fragment length polymorphism (PCR-RFLP).

Results: A statistically significant lower frequency of C/T genotype in late-onset male psoriasis vulgaris $(\mathrm{P}=0.029)$ as well as of $\mathrm{T}$ allele in female early-onset psoriasis vulgaris $(\mathrm{P}=0.049)$ were ascertained.

Conclusions: On condition that all other genetic or environmental factors remain stable, the existence and possible interaction between GJB2 rs3751385 C and T alleles in male psoriatic patients may be considered as protective gene component against late-onset psoriasis appearance, while presence of the $\mathrm{T}$ allele in female might block the histogenetic mechanisms of early-onset psoriasis lesions.

Keywords: Connexin 26; GJB2; rs3751385; Psoriasis genetics; Early-onset psoriasis; Late-onset psoriasis; Psoriasis pathogenesis

Manuscript submitted May 27, 2019, accepted June 25, 2019

aDepartment of Biology, Faculty of Medicine, Democritus University of Thrace, Alexandroupolis, Greece

bDepartment of Dermatology, Faculty of Medicine, Democritus University of Thrace, Alexandroupolis, Greece

'Department of Medical Statistics, Faculty of Medicine, Democritus University of Thrace, Alexandroupolis, Greece

${ }^{\mathrm{d} C}$ Corresponding Author: Stavroula Veletza, Department of Biology, Faculty of Medicine, Democritus University of Thrace, 68100 Alexandroupolis, Greece. Email: sveletza@med.duth.gr

doi: https://doi.org/10.14740/jocmr3845

\section{Introduction}

Psoriasis is a genetically determined lifelong disease whose genetic component interacts with environmental triggers [1-4]. Psoriasis recurrence in first-degree relatives of patients suffering from the disease is about 10 times greater than that in general population [5]. Genome-wide association studies (GWAS) have revealed the possible correlation of psoriasis with a linkage between a multifactorial genetic predisposition and certain haplotypes of human leukocytes antigens (HLAs) [6]. Classical major histocompatibility complex alleles studies suggested a strong association of early-onset psoriasis with HLA-Cw6, the primary PSOR1 risk allele [7]. Genetic and phenotypic heterogeneity of psoriasis as well as high number of involved genes with low penetrance, constitute factors that obscure the recognition of clearly defined inheritance patterns of psoriasis and thus make it difficult to determine the extent of contribution of non-major histocompatibility complex loci $[8,9]$. At least 20 possible loci, located on 15 different chromosomes, have been suggested as related to psoriasis [10]. Specific genetic polymorphisms in candidate genes have been indicated as implicated in the pathogenesis of psoriasis vulgaris $[10,11]$.

A gap junction network, consisting of connexin protein subunits, is a major component of epidermis cell-cell communication. Gap junctions rule cell-cell communication within cells in multicellular organisms. This communication is necessary for maintaining cellular homeostasis, ensuring cell reactions to stimuli and controlling cellular growth and tissue structural development $[12,13]$. Vertebrate gap junction channels are formed by various combinations of several connexins [14]. Connexons or connexin hemichannels are connexin hexamers that appear at gap junction domains of cell membranes, where the intercellular space constitutes a pore, $2-3 \mathrm{~nm}$ wide.

Gap junctions in invertebrates are formed by transmembrane proteins, defined as innexins. Formation of a channel through cell membrane is performed by a group of innexins that constitute an innexon [14]. In a similar way, in vertebrates, pannexins constitute a family of proteins, homologous to invertebrate innexins; six pannexin subunits form a pannexon, a cell membrane channel, a main enabler of extracellular ATP release [15-17].

Gap junctions are defined as non-specific pores connecting adjacent cells but also as integral membrane proteins that enable direct cytoplasmic exchange of ions and low molecular weight (up to $1 \mathrm{kDa}$ ) metabolites through the pores [17]. Different connexins correspond to different pore diameter. To date, 21 connexins have been identified in humans. Connexins are character- 
ized by a common sequence of structural elements, consisting of four hydrophobic transmembrane (M1-M4), two extracellular (E1, E2), three cytoplasmic domains, comprising amino-terminus (NT), cytoplasmic loop (CL) and carboxy-terminus (CT). CL and CT are virtually specific to each connexin isoform. Using immunostaining and immunoblotting, Cx43, Cx26, Cx31, $\mathrm{Cx} 37, \mathrm{Cx} 30, \mathrm{Cx} 30.3$ have been isolated from human epidermis, Cx43, Cx26 from hair follicle, Cx43 from sebaceous glands, Cx31, Cx26 from eccrine sweat glands and finally, CX43, Cx40 from dermal fibroblasts. Cx26 (13q11-q12) has been expressed in the inner ear, mammary gland, liver, mucous membranes, kidney, pancreas, intestine, skin and appendages [18-20].

F142L mutation of GJB2 gene has been incriminated in bilateral, profound, sensorineural hearing loss in association with an original spectrum of mucocutaneous semeiology. More precisely, a 2-year-old Caucasian female presented with periorificial and truncal erythematous patches, scaly plaques involving the face, upper extremities, external genital organs, gluteal region, perineum, pubic area, crusted plaques of the scalp, bilateral gluteal calcinosis cutis, scaling-obstruction of external auditory canals as well as development of granulomatous tissue around a gastrostomy [21]. c3 LG $>$ A (p.G11R) mutation of GJB6 gene (encoding connexin-30) has been incriminated for an autosomal dominant hidrotic dysplasia, including alopecia, palmoplantar hyperkeratosis and transverse curvature along the longitudinal axis of the nail (Clouston syndrome) [22]. Four mutations of GJB6 (C11R, V37E, D50N, A88V) as well as mutations in GJA1 (V41L) and GJB2 (r127H) have been related to Clouston syndrome [23, 24].

Mutant R75W of GJB2 (C>A) has been established as the basis of a heterozygous missense mutation, leading to functional defects of $\mathrm{Cx} 26$, clinically appearing in form of dominant deaf-mutism and palmoplantar keratoderma [24]. D66H missense mutation of GJB2 is responsible for mutilating keratoderma and sensorineural deafness (Vohwinkel's syndrome) [25]. Bart-Pumphrey syndrome (white discoloration of the nails, knuckle verrucous growths, hearing loss, palmoplantar keratoderma) is genetically encoded by a heterozygous substitution $\mathrm{C}$ to $\mathrm{A}$, leading to a non-conservative replacement of asparagine 54 with a negatively charged lysine (N54K) in the first extracellular loop of Cx26 [26]. D50Y is the most frequent among at least nine GJB2 mutations, possibly incriminated in the process of keratitis, ichthyosis and deafness syndrome (KID), whose setting might include photophobia corneal neovascularization and scarring, palmoplantar keratoderma, ichthyosis, squamous cell carcinoma of mouth lining [27]. Porokeratotic eccrine ostial and dermal duct nevus (PEODDN) syndrome, associated with the same mutations as those implicated in KID syndrome, is characterized by coexistence of dermal duct nevus, epidermal nevus and porokeratosis eccrine ostial nevus. In this disorder, somatic Cx26 mutations may produce linear bands of degenerated keratinocytes. Clinically, brownish punctuate papules and plaques appear in a linear pattern, especially on the extremities, usually at birth or childhood and rarely in adults. Histologically, parakeratotic columns occupy epidermal invaginations and an underlying acrosyringeal duct may be located at the base of the invagination [28-30]. PEODDN may be caused by p.Gly45Glu mutation (present exclusively within the epidermis) in an equimolar ratio to the wild type allele [28-30]. All of the pre-mentioned genetically encoded syndromes (due to Cx26 mutations) are characterized by hyperkeratotic thickening of certain skin areas, thus suggesting implication of $\mathrm{Cx} 26$ in the rate of differentiation and proliferation of the human epidermis [31-36].

High mRNA and protein levels of $\mathrm{Cx} 26$ have been detected by northern blot and immunofluorescence in fully mature psoriatic plaques, but not in non lesional regions of psoriatic patients or controls [31].

GJB2 rs72474224 and rs3751385 have been previously associated with psoriasis vulgaris in Chinese populations [37, 38]. Taking into consideration these data in association with the lack of evidence in non-Chinese populations, we decided to study the distribution of rs3751385 in psoriatic patients in a Caucasian Greek population at the prefecture of Thrace in Northern Greece.

\section{Materials and Methods}

\section{Patients' characteristics}

One hundred and seventy-three consecutive psoriatic patients examined at the University Clinic of Dermatology of the University General Hospital of Alexandroupolis in Thrace, Northern Greece, 111 males (64.9\%) and 62 females (35.8\%), were included in this study. Patients were randomly selected, regardless of body mass characteristics. Patients' age ranged from 15 to 90 years with a median age of $56.25 \pm 16.35$ years. All patients were clinically diagnosed and suffered from psoriasis vulgaris. Regarding age of onset, 108 patients were characterized as early-onset, first diagnosed before the age of 40 . Psoriasis patients with accompanying disease were excluded from the study in order to avoid possible interactions with potentially coexisting genetically determined dermatological disorders. One hundred and seventy-one healthy unrelated subjects, free from psoriasis, individually matched to patients by both gender and age, were recruited as controls (111 males $(64.9 \%)$ and 60 females $(35.1 \%)$ ). There were no significant differences in gender and age. Hardy-Weinberg equilibrium: controls $\chi^{2}=$ 0.341 , $\mathrm{df}=1, \mathrm{P}=0.559$, patients $\chi^{2}=0.086$, $\mathrm{df}=1, \mathrm{P}=0.769$. The characteristics of patients suffering from psoriasis vulgaris are summarized in Table 1. This study was conducted in compliance with the ethical standards of the responsible institution on human subjects as well as with the Helsinki Declaration.

\section{Methods}

Genotyping: Genomic DNA was extracted from peripheral blood leukocytes either using the kit Nucleospin ${ }^{\circledR}$ Blood of Macherey-Nagel or by salting out [39]. Genotyping was carried out by PCR-RFLP, using primers F': 5'-GTTTAACGATTGCCCAGTT-3' and R': 5'-TAACAGCCTGGGGTCTCAGT-3'. The 276-bp long amplicon was subsequently digested with NheI and separated by electrophoresis in 2\% agarose gel. Three genotypes were defined, according to their distinct patterns of bands: CC (276 bp), C/T (276, 187 and $93 \mathrm{bp})$ and TT 
Table 1. Characteristics of Patients With Psoriasis and Healthy Controls

\begin{tabular}{llll}
\hline & Patients & Controls & P value \\
\hline No. & 173 & 171 & 0.810 \\
Age (years; mean \pm SD) & $48.97 \pm 16.06$ & $48.56 \pm 15.96$ & 0.884 \\
Gender & & & $111(64.9 \%)$ \\
$\quad$ Male & $111(64.2 \%)$ & $60(35.1 \%)$ & \\
$\quad$ Female & $62(35.8 \%)$ & - \\
Age onset & & - \\
$\quad$ Early & $108(62.4 \%)$ & \\
$\quad$ Late & $65(37.6 \%)$ & \\
\hline
\end{tabular}

Hardy-Weinberg equilibrium. Controls: $X^{2}=0.341, d f=1, P=0.559$. Patients: $X^{2}=0.086, d f=1, P=0.769$.

(187 and $93 \mathrm{bp})$.

\section{Statistical analysis}

Statistical analysis was performed using Software Microsoft Office Excel 2007 and Statistical Package for Social Sciences (SPSS, version 16.0). The observed genotype distributions were compared with those expected from Hardy-Weinberg equilibrium using a standard $\chi^{2}$ test. Adjusted odds ratio (OR) for the genotypes was calculated after correction for psoriasis risk factors with binary logistic regression. All quantitative statistical analyses were carried out using the two-tailed Student's $t$-test. Data are presented as mean $\pm \mathrm{SD} . \mathrm{P}<0.05$ was considered statistically significant.

\section{Results}

GJB2 gene is located at chromosome 13. Rs3751385: C>T is located at the 3'UTR region of the GJB2 gene. Our study included 173 patients suffering from psoriasis vulgaris, ranged from 15 to 90 years of age, 111 males and 62 females, 108 with early-onset and 65 with late-onset psoriasis. Patients were compared to 171 controls, individually matched to patients by both gender and age, as described in "patients" characteristics" and summarized in Table 1.

The distribution of rs3751385 genotypes and alleles in patients suffering from psoriasis vulgaris and matched healthy controls is shown in Table 2.

Comparison of the entire cohort of psoriatic patients with controls revealed no statistically significant difference, regarding distribution of the rs3751385 genotypes and alleles among the entire cohort $\left(\chi^{2}=3.033, \mathrm{df}=2, \mathrm{P}=0.219\right.$ for genotypes; $\chi^{2}=2.913, \mathrm{df}=1, \mathrm{P}=0.088$ for genotype recessive model; $\chi^{2}$ $=2.919, \mathrm{df}=1, \mathrm{P}=0.088$ for allele contrast).

When patients were stratified by gender, we observed that neither male nor female psoriatic patients differ significantly with controls (among males: $\chi^{2}=1.164$, $\mathrm{df}=2, \mathrm{P}=0.559$ for genotypes, $\chi^{2}=1.108, \mathrm{df}=1, \mathrm{P}=0.293$ for recessive model, $\chi^{2}=0.883, \mathrm{df}=1, \mathrm{P}=0.347$ for allele contrast and among females $\chi^{2}=2.630, \mathrm{df}=2, \mathrm{P}=0.269$ for genotypes, $\chi^{2}=2.109$, $\mathrm{df}=1, \mathrm{P}=0.146$ for recessive model, $\chi^{2}=2.455, \mathrm{df}=1, \mathrm{P}=$
0.117 for allele contrast) (Table 2).

Subsequently, analysis was stratified according to subjects' age of psoriasis onset (Table 3 for early-onset psoriasis and Table 4 for late-onset psoriasis). In Table 3, we present data regarding patients with early-onset psoriasis: comparison of the cohort of early-onset psoriasis versus matched controls again detected no statistically significant differences between the two groups $\left(\chi^{2}=2.047, \mathrm{df}=2, \mathrm{P}=0.359\right.$ for genotypes, $\chi^{2}=1.227, \mathrm{df}=1, \mathrm{P}=0.268$ for recessive model, $\chi^{2}=1.619$, $\mathrm{df}=1, \mathrm{P}=0.203$ for allele contrast). Similarly, further stratification of the early-onset cohort by gender did not show any significant differences from controls for either male patients $\left(\chi^{2}=0.047, \mathrm{df}=2, \mathrm{P}=0.977\right.$ for genotypes, $\chi^{2}=0.000, \mathrm{df}=1$, $\mathrm{P}=0.991$ for recessive model, $\chi^{2}=0.004, \mathrm{df}=1, \mathrm{P}=951$ for allele contrast).

Within female gender early-onset psoriasis, a statistically significant higher frequency of the $\mathrm{T}$ allele was suggested in controls vs. patients $\left(\chi^{2}=3.858, \mathrm{df}=1, \mathrm{P}=0.049\right)$ (Table 3$)$, even though no statistically significant difference was detected regarding genotypes $\left(\chi^{2}=4.190, \mathrm{df}=2, \mathrm{P}=0.123\right)$ and relevant higher frequency for $\mathrm{C} / \mathrm{T}$ genotype in controls vs. patients was only marginally non-significant $\left(\chi^{2}=3.264, \mathrm{df}=1, \mathrm{P}=0.071\right)$.

In Table 4, we present data regarding patients with lateonset psoriasis. In late-onset psoriasis vulgaris cohort, no statistically significant differences were ascertained regarding genotypes $\left(\chi^{2}=3.418\right.$, df $\left.=2, \mathrm{P}=0.181\right)$ or allele contrast $\left(\chi^{2}=2.307, \mathrm{df}=1, \mathrm{P}=0.129\right)$, while the higher frequency of $\mathrm{C} / \mathrm{T}$ genotype in controls was marginally non-significant $\left(\chi^{2}=\right.$ 3.134 , $\mathrm{df}=1, \mathrm{P}=0.077)$. In female gender late-onset psoriasis, no statistically significant differences were detected $\left(\chi^{2}=\right.$ $0.193, \mathrm{df}=2, \mathrm{P}=0.908$ for genotypes, $\chi^{2}=0.177, \mathrm{df}=1, \mathrm{P}=$ 0.674 for recessive model, $\chi^{2}=0.185, \mathrm{df}=1, \mathrm{P}=0.668$ for allele contrast). In contrast, in male gender late-onset psoriasis, the observed differences were significant; more precisely, the higher frequency of $\mathrm{C} / \mathrm{T}$ genotype in controls was statistically significant $\left(\chi^{2}=4.758, \mathrm{df}=1, \mathrm{P}=0.029\right.$ for recessive model $)$, while differences for genotype $\left(\chi^{2}=5.469\right.$, df $\left.=2, \mathrm{P}=0.065\right)$ or allele contrast $\left(\chi^{2}=3.483, \mathrm{df}=1, \mathrm{P}=0.062\right)$ were marginally non-significant (Table 4).

Consequently, presence of the $\mathrm{C} / \mathrm{T}$ genotype, that is interaction of $\mathrm{C}$ and $\mathrm{T}$ alleles in males might be considered as protective gene component against the appearance of late-onset psoriasis, while presence of the T allele in females might block 
Table 2. Distribution of GJB-2 SNP Genotypes Among Patients With Psoriasis and Healthy Controls According to Subject's Gender

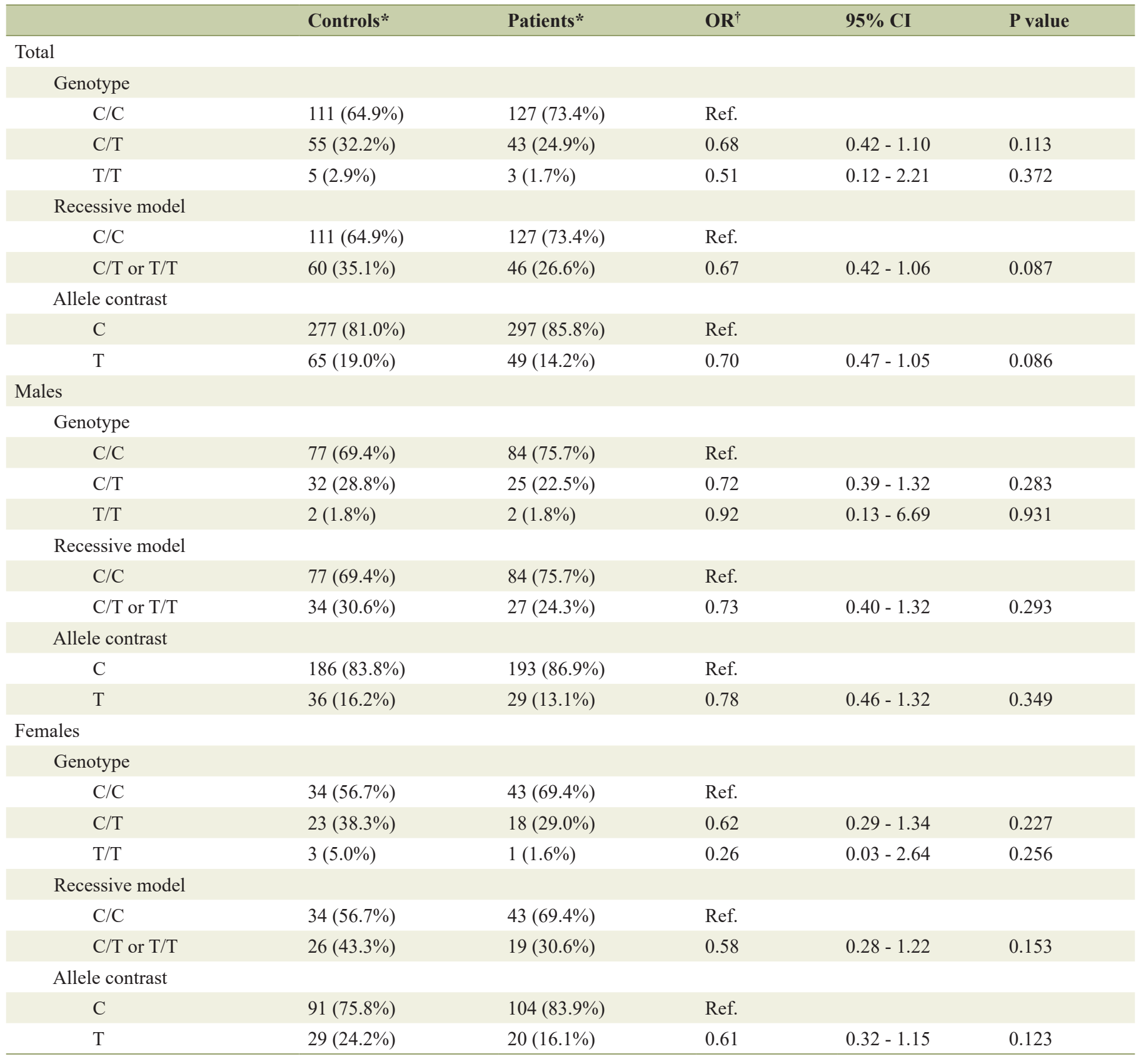

Statistical significance for differences in genotype, G-containing genotype and allelic frequencies between patients with psoriasis vulgaris and healthy controls: 1) $X^{2}=3.033, \mathrm{df}=2, \mathrm{P}=0.219 ; \mathrm{X}^{2}=2.913, \mathrm{df}=1, \mathrm{P}=0.088 ; \mathrm{X}^{2}=2.919, \mathrm{df}=1, \mathrm{P}=0.088$ among the entire cohort; 2$) \mathrm{X}^{2}=1.164, \mathrm{df}=2$, $P=0.559 ; X^{2}=1.108, d f=1, P=0.293 ; X^{2}=0.883, d f=1, P=0.347$ among males; 3$) X^{2}=2.630, d f=2, P=0.269 ; X^{2}=2.109, d f=1, P=0.146 ;$ $\mathrm{X}^{2}=2.455, \mathrm{df}=1, \mathrm{P}=0.117$ among females. ${ }^{*}$ Data are number of subjects and percentage $(\%)$. ${ }^{\dagger}$ Adjusted for age and gender. OR: odds ratio; Cl: confidence interval.

histogenesis of early-onset psoriasis lesions.

\section{Discussion}

Recent experiments in juvenile and adult mice suggested the maintenance and insistence of connexin 26 expression that re- sults in obstinacy of an ulcerative situation of the hyperproliferative epidermis. Kruppel-like factor 4 (Klf4) helps establish the epidermal barrier in utero [32]. The above Klf4 activity is simultaneously expressed with Klf4 caused proximal Cx26 promoter transcription repression, leading the downregulation of Cx26 contribution. Heterozygous involucrin Cx26 keratinocytes ATP release was clearly more intensive than that of mice 
Table 3. Distribution of GJB-2 SNP Genotypes Among Patients With Early-Onset Psoriasis and Healthy Controls According to Subject's Gender

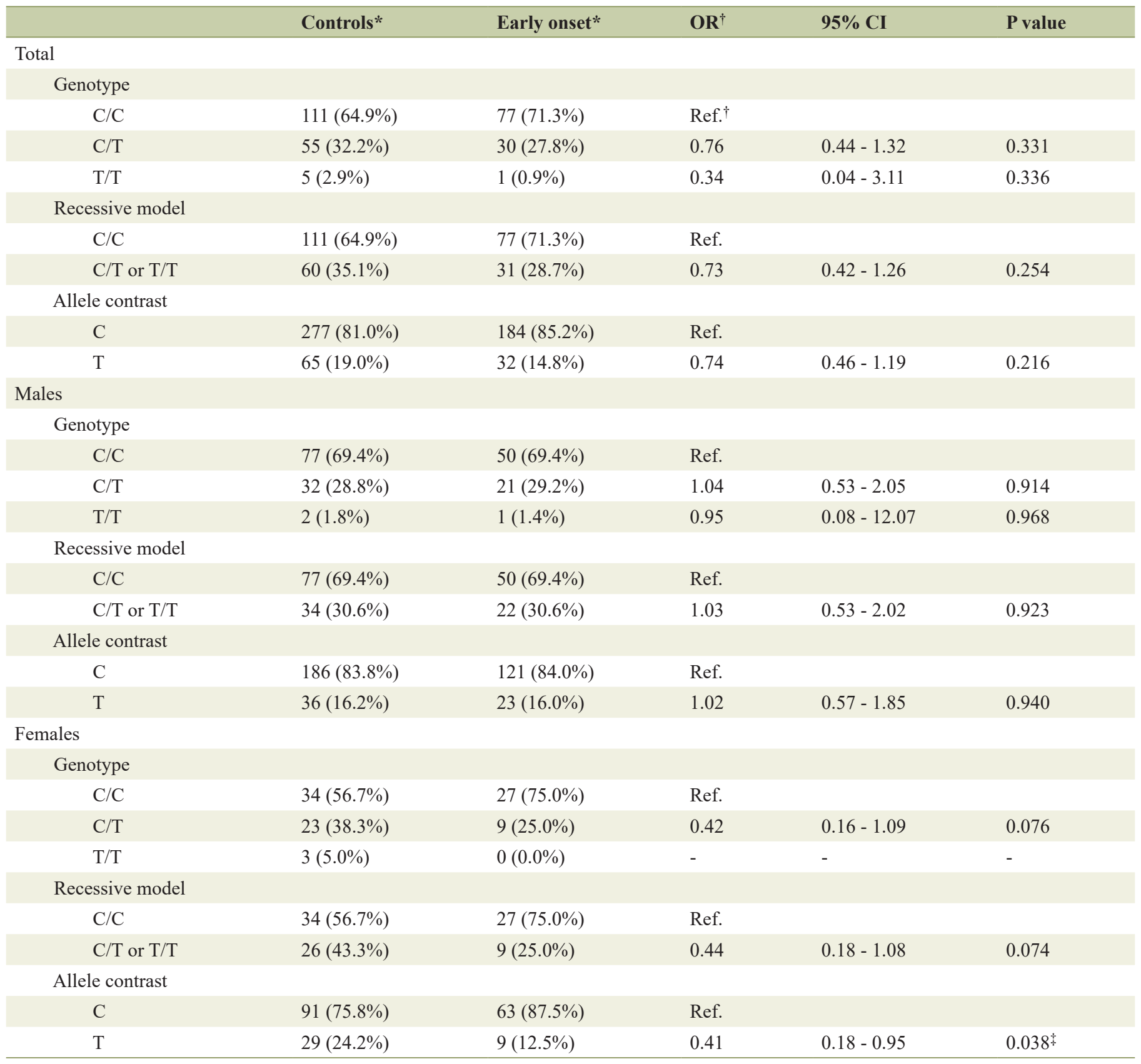

Statistical significance for differences in genotype, G-containing genotype and allelic frequencies between patients with early onset psoriasis and healthy controls: 1) $X^{2}=2.047, \mathrm{df}=2, \mathrm{P}=0.359 ; \mathrm{X}^{2}=1.227, \mathrm{df}=1, \mathrm{P}=0.268 ; \mathrm{X}^{2}=1.619, \mathrm{df}=1, \mathrm{P}=0.203$ among the entire cohort; 2) $\mathrm{X}^{2}=0.047$, $\mathrm{df}=2, \mathrm{P}=0.977 ; \mathrm{X}^{2}=0.000, \mathrm{df}=1, \mathrm{P}=0.991 ; \mathrm{X}^{2}=0.004, \mathrm{df}=1, \mathrm{P}=0.951$ among males; 3$) \mathrm{X}^{2}=4.190, \mathrm{df}=2, \mathrm{P}=0.123 ; \mathrm{X}^{2}=3.264, \mathrm{df}=1, \mathrm{P}=$ $0.071 ; X^{2}=3.858, \mathrm{df}=1, P=0.049$ among females. ${ }^{*}$ Data are number of subjects and percentage $(\%)$. ${ }^{\dagger}$ Adjusted for age and gender. ${ }^{\ddagger}$ Statistically significant $\mathrm{P}$ values. OR: odds ratio; $\mathrm{Cl}$ : confidence interval.

controls, thus upregulating epidermal differentiation and therefore being implicated in the histogenesis of the hyperkeratotic psoriasiform plaques [32]. Consequently, the possible role of carbenoxolone (an ATP-release suppressing blocker of gap junction and hemi-channel) in hyperkeratotic diseases management has to be searched in the future. Immunocytochemi- cal studies demonstrated the upregulation of $\mathrm{Cx} 26$ expression in psoriatic plaques $[20,31,40]$.

Transcriptome analysis in psoriasis has indicated upregulation of GJB2 [41]. Psoriatic plaques cutaneous flora modifications may trigger upgrade connexin26 activity [20, 42]. S. aureus isolated peptidoglycan (in contrast to that isolated from 
Table 4. Distribution of GJB-2 SNP Genotypes Among Patients With Late-Onset Psoriasis and Healthy Controls According to Subject's Gender

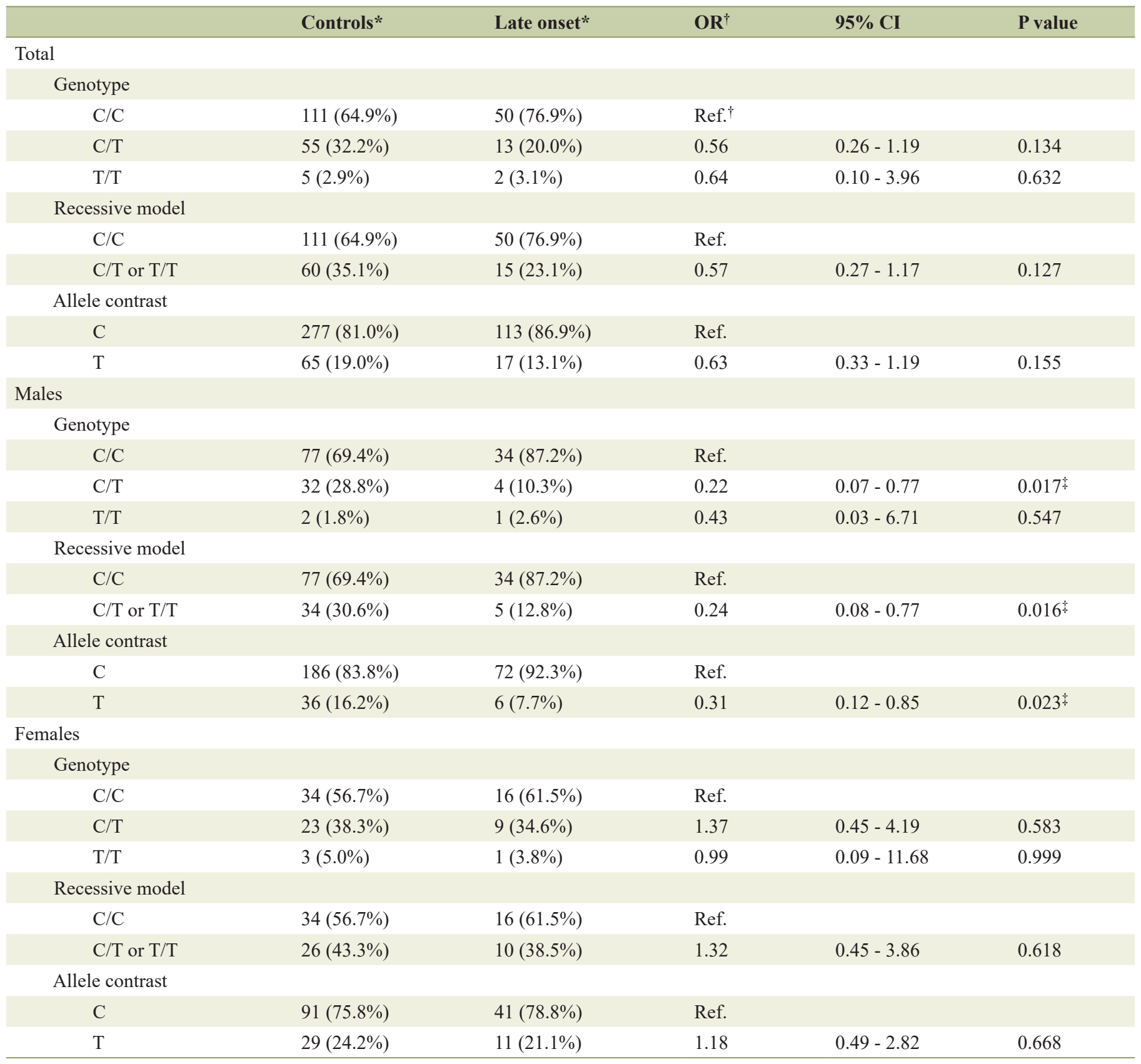

Statistical significance for differences in genotype, G-containing genotype and allelic frequencies between patients with late onset psoriasis and healthy controls: 1) $X^{2}=3.418, d f=2, P=0.181 ; X^{2}=3.134, d f=1, P=0.077 ; X^{2}=2.307, d f=1, P=0.129$ among the entire cohort; 2) $X^{2}=5.469$, $\mathrm{df}=2, \mathrm{P}=0.065 ; \mathrm{X}^{2}=4.758, \mathrm{df}=1, \mathrm{P}=0.029 ; \mathrm{X}^{2}=3.483, \mathrm{df}=1, \mathrm{P}=0.062$ among males; 3$) \mathrm{X}^{2}=0.193, \mathrm{df}=2, \mathrm{P}=0.908 ; \mathrm{X}^{2}=0.177, \mathrm{df}=1, \mathrm{P}=$ $0.674 ; X^{2}=0.185, \mathrm{df}=1, P=0.668$ among females. ${ }^{*}$ Data are number of subjects and percentage $(\%)$. ${ }^{\dagger}$ Adjusted for age and gender. ${ }^{\ddagger}$ Statistically significant $\mathrm{P}$ values. OR: odds ratio; $\mathrm{Cl}$ : confidence interval.

the skin commensal E. epidermidis) stimulates $\mathrm{HaCa}$ T cells to strengthen $\mathrm{Cx} 26$ expression. The above peptidoglycan action was correlated with modifying IL-6 induction, whose activity was blocked by connexin hemichannel blockers [20, 43].

The DFNB1 locus at chromosome 13q11-q12 contains two genes: GJB2 (gap junction protein beta 2) and GJB6 (gap junction protein beta 6), whose mutations constitute the most frequent causes of (autosomal recessive non-syndromic hearing loss (ARNSHL). More precisely, the GJB2 SNP rs3751385 was included among the statistically significant more frequent SNPs in deaf patients vs. healthy controls [44-47].

GJB1 and GJB3 genes have also been found mutated in 
patients suffering from either non-syndromic or syndromic deafness, suggesting possible involvement of the corresponding proteins connexin 32 (GJB1) and connexin 31 (GJB3) in embryology, histogenesis and function of the auditory system structural components [48].

In a case-control study in psoriasis vulgaris in a Chinese Han population, GJB2 rs72474224 SNP was suggested statistically significantly different between patients and controls, with the $\mathrm{T}$ allele being preferentially associated with psoriasis appearance susceptibility. Rs 72474224 may cause conversion of valine to isoleucine at amino acid 37 of the GJB2 protein. Isoleucine has an additional methyl group compared to valine and this structural peculiarity may influence the functional mission of the Cx26 gap junction channel pore [37]. In another study in a Chinese population, a decreased frequency of the GJB2 rs3751385 C allele in psoriatic patients was statistically significant [38].

In our study, we observed statistically significant: lower frequency of the $\mathrm{C} / \mathrm{T}$ genotype in male patients with late-onset psoriasis vulgaris and lower frequency of the $\mathrm{T}$ allele in female patients with early-onset form of the disease. GJB2 rs3751385 $\mathrm{C} / \mathrm{T}$ is located at the 3'UTR region of GJB2 gene. 3'UTRs are considerably longer than their 5'UTR counterparts, suggesting a more significant potential for gene regulation, as alternative polyadenylation, transcript cleavage and mRNA nuclear export $[49,50]$. 2-methoxyestradiol, an endogenous metabolite of estrogen is an in vitro inhibitor of both angiogenesis and proliferation and migration of endothelial cells; all of the above occur in psoriasis. This involvement of sex hormones in psoriasis vulgaris may provide some ground for interpretation of the differences in distribution of genotypes in different genders [51, 52]. Early-onset psoriatic patients carriers of the HLA-Cw6 allele and late-onset psoriatic patients are characterized by clinical, demographic, immunocytochemical and genetic differences $[53,54]$. Our results are incorporated in the above setting of the two distinct subtypes of psoriasis vulgaris [55].

On condition that all other genetic or environmental factors remain stable, the presence and possible interaction between the two alleles in heterozygous males may be considered as a protective gene component against late-onset psoriasis appearance while ascertainment of the $\mathrm{T}$ allele in females might obstruct the appearance of early-onset psoriasis.

The number of patients and matched controls included in our study constitutes a relatively small size sample. Further additional studies would be extremely interesting and are needed to reinforce our reported results.

\section{Acknowledgments}

We thank Dr Elisavet Gatzidou for excellent technical assistance.

\section{Financial Disclosure}

The present work was supported in part by AbbVie Pharmaceutical S.A.

\section{Conflict of Interest}

None to declare.

\section{Informed Consent}

Informed consent was obtained by every patient enrolled in this study.

\section{Author Contributions}

E-AS performed research. AK provided samples, expert clinical knowledge and wrote the paper. GT statistically analyzed the data, created tables. SV conceived and designed study, supervised research, and reviewed paper.

\section{References}

1. Oka A, Mabuchi T, Ozawa A, Inoko H. Current understanding of human genetics and genetic analysis of psoriasis. J Dermatol. 2012;39(3):231-241.

2. Chandran V. The genetics of psoriasis and psoriatic arthritis. Clin Rev Allergy Immunol. 2013;44(2):149-156.

3. Puig L, Julia A, Marsal S. The pathogenesis and genetics of psoriasis. Actas Dermosifiliogr. 2014;105(6):535-545.

4. Gao J, Sun L, Zhang X. The genetic progress of psoriasis in the Han Chinese population. J Investig Dermatol Symp Proc. 2015; 17(1):46-47.

5. Bhalerao J, Bowcock AM. The genetics of psoriasis: a complex disorder of the skin and immune system. Hum Mol Genet. 1998;7(10):1537-1545.

6. Alshobaili HA, Shahzad M, Al-Marshood A, Khalil A, Settin A, Barrimah I. Genetic background of psoriasis. Int J Health Sci (Qassim). 2010;4(1):23-29.

7. Gudjonsson JE, Karason A, Antonsdottir A, Runarsdottir EH, Hauksson VB, Upmanyu R, Gulcher J, et al. Psoriasis patients who are homozygous for the HLA-Cw*0602 allele have a 2.5 -fold increased risk of developing psoriasis compared with Cw6 heterozygotes. Br J Dermatol. 2003;148(2):233-235.

8. Roberson ED, Bowcock AM. Psoriasis genetics: breaking the barrier. Trends Genet. 2010;26(9):415-423.

9. Yang Q, Liu H, Qu L, Fu X, Yu Y, Yu G, Tian H, et al. Investigation of 20 non-HLA (human leucocyte antigen) psoriasis susceptibility loci in Chinese patients with psoriatic arthritis and psoriasis vulgaris. Br J Dermatol. 2013; 168(5):1060-1065.

10. Sun L, Zhang X. The immunological and genetic aspects in psoriasis. Applied Informatics. 2014;1:3-21.

11. Sundarrajan S, Arumugam M. Comorbidities of psoriasis - exploring the links by network approach. PLoS One. 2016;11(3):e0149175.

12. Yen MR, Saier MH, Jr. Gap junctional proteins of animals: the innexin/pannexin superfamily. Prog Biophys Mol Biol. 2007;94(1-2):5-14. 
13. Nielsen MS, Axelsen LN, Sorgen PL, Verma V, Delmar M, Holstein-Rathlou NH. Gap junctions. Compr Physiol. 2012;2(3):1981-2035.

14. Scemes E, Spray DC, Meda P. Connexins, pannexins, innexins: novel roles of "hemi-channels". Pflugers Arch. 2009;457(6):1207-1226.

15. Penuela S, Bhalla R, Gong XQ, Cowan KN, Celetti SJ, Cowan BJ, Bai D, et al. Pannexin 1 and pannexin 3 are glycoproteins that exhibit many distinct characteristics from the connexin family of gap junction proteins. J Cell Sci. 2007;120(Pt 21):3772-3783.

16. Barbe MT, Monyer H, Bruzzone R. Cell-cell communication beyond connexins: the pannexin channels. Physiology (Bethesda). 2006;21:103-114.

17. Lohman AW, Isakson BE. Differentiating connexin hemichannels and pannexin channels in cellular ATP release. FEBS Lett. 2014;588(8):1379-1388.

18. Richard G. Connexins: a connection with the skin. Exp Dermatol. 2000;9(2):77-96.

19. Segre JA. Epidermal barrier formation and recovery in skin disorders. J Clin Invest. 2006;116(5):1150-1158.

20. Martin PE, van Steensel M. Connexins and skin disease: insights into the role of beta connexins in skin homeostasis. Cell Tissue Res. 2015;360(3):645-658.

21. Brown CW, Levy ML, Flaitz CM, Reid BS, Manolidis S, Hebert AA, Bender MM, et al. A novel GJB2 (connexin 26) mutation, F142L, in a patient with unusual mucocutaneous findings and deafness. J Invest Dermatol. 2003;121(5):1221-1223.

22. Hu YH, Lin YC, Hwu WL, Lee YM. Pincer nail deformity as the main manifestation of Clouston syndrome. Br J Dermatol. 2015;173(2):581-583.

23. Liu YT, Guo K, Li J, Liu Y, Zeng WH, Geng SM. Novel mutations in GJB6 and GJB2 in Clouston syndrome. Clin Exp Dermatol. 2015;40(7):770-773.

24. Richard G, White TW, Smith LE, Bailey RA, Compton JG, Paul DL, Bale SJ. Functional defects of Cx26 resulting from a heterozygous missense mutation in a family with dominant deaf-mutism and palmoplantar keratoderma. Hum Genet. 1998;103(4):393-399.

25. Maestrini E, Korge BP, Ocana-Sierra J, Calzolari E, Cambiaghi S, Scudder PM, Hovnanian A, et al. A missense mutation in connexin26, D66H, causes mutilating keratoderma with sensorineural deafness (Vohwinkel's syndrome) in three unrelated families. Hum Mol Genet. 1999;8(7):1237-1243.

26. Richard G, Brown N, Ishida-Yamamoto A, Krol A. Expanding the phenotypic spectrum of Cx26 disorders: Bart-Pumphrey syndrome is caused by a novel missense mutation in GJB2. J Invest Dermatol. 2004;123(5):856863.

27. Aypek H, Bay V, Mese G. Altered cellular localization and hemichannel activities of KID syndrome associated connexin26 I30N and D50Y mutations. BMC Cell Biol. 2016; 17:5.

28. Easton JA, Donnelly S, Kamps MA, Steijlen PM, Martin PE, Tadini G, Janssens R, et al. Porokeratotic eccrine nevus may be caused by somatic connexin 26 mutations. J Invest Dermatol. 2012;132(9):2184-2191.
29. Levinsohn JL, McNiff JM, Antaya RJ, Choate KA. A Somatic p.G45E GJB2 Mutation Causing Porokeratotic Eccrine Ostial and Dermal Duct Nevus. JAMA Dermatol. 2015;151(6):638-641.

30. Bandyopadhyay D, Saha A, Das D, Das A. Porokeratotic eccrine ostial and dermal duct nevus. Indian Dermatol Online J. 2015;6(2):117-119.

31. Labarthe MP, Bosco D, Saurat JH, Meda P, Salomon D. Upregulation of connexin 26 between keratinocytes of psoriatic lesions. J Invest Dermatol. 1998;111(1):72-76.

32. Djalilian AR, McGaughey D, Patel S, Seo EY, Yang C, Cheng J, Tomic M, et al. Connexin 26 regulates epidermal barrier and wound remodeling and promotes psoriasiform response. J Clin Invest. 2006;116(5):1243-1253.

33. de Zwart-Storm EA, Martin PE, VanSteensel M. Gap junction diseases of the skin: Novel insights from new mutations. Expert Review of Dermatology. 2009;4(5):455468.

34. Press E, Alaga KC, Barr K, Shao Q, Bosen F, Willecke K, Laird DW. Disease-linked connexin26 S17F promotes volar skin abnormalities and mild wound healing defects in mice. Cell Death Dis. 2017;8(6):e2845.

35. Scott CA, Tattersall D, O'Toole EA, Kelsell DP. Connexins in epidermal homeostasis and skin disease. Biochim Biophys Acta. 2012;1818(8):1952-1961.

36. Srinivas M, Verselis VK, White TW. Human diseases associated with connexin mutations. Biochim Biophys Acta Biomembr. 2018;1860(1):192-201

37. Yao F, Yue M, Zhang C, Zuo X, Zheng X, Zhang A, Wang Z, et al. A genetic coding variant rs72474224 in GJB2 is associated with clinical features of psoriasis vulgaris in a Chinese Han population. Tissue Antigens. 2015;86(2):134-138.

38. Liu QP, Wu LS, Li FF, Liu S, Su J, Kuang YH, Chen C, et al. The association between GJB2 gene polymorphism and psoriasis: a verification study. Arch Dermatol Res. 2012;304(9):769-772.

39. Miller SA, Dykes DD, Polesky HF. A simple salting out procedure for extracting DNA from human nucleated cells. Nucleic Acids Res. 1988;16(3):1215.

40. Lucke T, Choudhry R, Thom R, Selmer IS, Burden AD, Hodgins MB. Upregulation of connexin 26 is a feature of keratinocyte differentiation in hyperproliferative epidermis, vaginal epithelium, and buccal epithelium. J Invest Dermatol. 1999;112(3):354-361.

41. Li B, Tsoi LC, Swindell WR, Gudjonsson JE, Tejasvi T, Johnston A, Ding J, et al. Transcriptome analysis of psoriasis in a large case-control sample: RNA-seq provides insights into disease mechanisms. J Invest Dermatol. 2014;134(7):1828-1838.

42. Gallo RL, Nakatsuji T. Microbial symbiosis with the innate immune defense system of the skin. J Invest Dermatol. 2011;131(10):1974-1980.

43. Donnelly S, English G, de Zwart-Storm EA, Lang S, van Steensel MA, Martin PE. Differential susceptibility of Cx26 mutations associated with epidermal dysplasias to peptidoglycan derived from Staphylococcus aureus and Staphylococcus epidermidis. Exp Dermatol. 2012;21(8):592-598. 
44. Minarik G, Ferakova E, Ficek A, Polakova H, Kadasi L. GJB2 gene mutations in Slovak hearing-impaired patients of Caucasian origin: spectrum, frequencies and SNP analysis. Clin Genet. 2005;68(6):554-557.

45. Van Laer L, Carlsson PI, Ottschytsch N, Bondeson ML, Konings A, Vandevelde A, Dieltjens N, et al. The contribution of genes involved in potassium-recycling in the inner ear to noise-induced hearing loss. Hum Mutat. 2006;27(8):786-795.

46. Dickson SP, Wang K, Krantz I, Hakonarson H, Goldstein DB. Rare variants create synthetic genome-wide associations. PLoS Biol. 2010;8(1):e1000294.

47. Grillo AP, de Oliveira FM, de Carvalho GQ, Medrano RF, da Silva-Costa SM, Sartorato EL, de Oliveira CA. Single nucleotide polymorphisms of the GJB2 and GJB6 genes are associated with autosomal recessive nonsyndromic hearing loss. Biomed Res Int. 2015;2015:318727.

48. Lopez-Bigas N, Arbones ML, Estivill X, Simonneau L. Expression profiles of the connexin genes, Gjb1 and Gjb3, in the developing mouse cochlea. Mech Dev. 2002;119(Suppl 1):S111-115.

49. Grzybowska EA, Wilczynska A, Siedlecki JA. Regulatory functions of 3'UTRs. Biochem Biophys Res Commun.
2001;288(2):291-295.

50. Conne B, Stutz A, Vassalli JD. The 3' untranslated region of messenger RNA: A molecular 'hotspot' for pathology? Nat Med. 2000;6(6):637-641.

51. Fotsis T, Zhang Y, Pepper MS, Adlercreutz H, Montesano R, Nawroth PP, Schweigerer L. The endogenous oestrogen metabolite 2-methoxyoestradiol inhibits angiogenesis and suppresses tumour growth. Nature. 1994;368(6468):237-239.

52. Armstrong AW, Voyles SV, Armstrong EJ, Fuller EN, Rutledge JC. Angiogenesis and oxidative stress: common mechanisms linking psoriasis with atherosclerosis. J Dermatol Sci. 2011;63(1):1-9.

53. Queiro R, Tejon P, Alonso S, Coto P. Age at disease onset: a key factor for understanding psoriatic disease. Rheumatology (Oxford). 2014;53(7):1178-1185.

54. Theodorakopoulou E, Yiu ZZ, Bundy C, Chularojanamontri L, Gittins M, Jamieson LA, Motta L, et al. Early- and late-onset psoriasis: a cross-sectional clinical and immunocytochemical investigation. Br J Dermatol. 2016;175(5):1038-1044.

55. Kirby B. Is late-onset psoriasis a distinct subtype of chronic plaque psoriasis? Br J Dermatol. 2016;175(5):869-870. 